\title{
RESPONSABILIDADE CIVIL NA SOCIEDADE DE RISCO*
}

CIVIL RESPONSIBILITY IN RISK SOCIETY

Teresa Ancona Lopez ${ }^{* *}$

1. Sociedade de risco e responsabilidade civil

O tema escolhido visa mostrar a evolução da Responsabilidade Civil diante da nova realidade produtora de danos, a chamada sociedade de risco. Como sabemos, esse termo foi cunhado, na Alemanha, por Ulrich Beck, que publicou, em 1986, a Sociedade de Risco (Risikogesellschaft), um dos livros mais influentes na análise social da última parte do século XX e referência do problema do risco global.

Uma das mais acentuadas características da sociedade contemporânea é o acelerado progresso tecnológico e científico. Essas descobertas e transformações visam, obviamente, melhorar a vida de todos no planeta Terra. Porém, tudo isso traz, paradoxalmente, grandes riscos e perigos para a civilização. Vivemos a era do medo, sentimento conhecido de toda criatura viva conforme ensina Zygmunt Bauman, ${ }^{1}$ e da incerteza. Não sabemos aonde podem nos levar esses avanços.

Esse medo e essa incerteza não vêm somente das grandes catástrofes naturais, que também apavoram, como os tsunamis ou terremotos vistos no Japão e no Haiti, mas principalmente dos riscos de danos morais e materiais que surgem das novas invenções como a internet e toda informática, porquanto somos permanentemente controlados. Nossos dados são públicos. Hoje, o famoso "Grande Irmão" toma conta de nossas vidas e nos leva aprender a lidar com o fundamental direito de privacidade nessa também sociedade de vigilância. É certo que ninguém ignora os danos da economia globalizada. Lembre-se, recentemente, da crise econômica deflagrada em 2008, que se espalhou por todas as economias do mundo. $\mathrm{Ou}$, ainda, dos riscos trazidos pelas novas descobertas advindas de pesquisas biotecnológicas como as clonagens. Sem falar nos riscos que surgem com os novos medicamentos ou com alimentos contaminados por venenos ou mesmo por praguicidas. O que dizer de toda controvérsia que pesa sobre a questão dos alimentos transgênicos?

Mais recentemente, pesquisas - ainda não concludentes, diga-se de passagem - têm mostrado que o uso excessivo do telefone celular tem o risco de gerar, no futuro, graves doenças em decorrência da propagação de ondas eletromagnéticas principalmente

Esta aula foi baseada no livro da Autora Princípio da precaução e evolução da responsabilidade civil. São Paulo: Quartier Latin, 2010.

* Professora Titular do Departamento de Direito Civil da Faculdade de Direito da Universidade de São Paulo e Advogada.

Medo Liquido. Tradução de Carlos Alberto Medeiros, Rio de Janeiro: Ed. Zahar, 2008 , p. 9. 
em crianças que não têm seu cérebro inteiramente formado. No mesmo sentido, as torres retransmissoras de sinais para esses aparelhos móveis foram colocadas sob suspeita de prejudicar a saúde de todos os que habitam próximo a elas. Na França, mesmo diante da incerteza científica (risco hipotético), o Tribunal de Grasse, em 17/06/2003, decidiu decisão essa confirmado pela Corte de Apelação de Aix en Provence em 08/06/2004 -, combinando a teoria da precaução com os chamados direito de vizinhança, determinou a retirada de antena de telefonia celular que emitia ondas eletromagnéticas supostamente perigosas à saúde da população vizinha. É o típico caso de risco incerto. Mas, hoje, concebe-se o mundo sem a telefonia celular?

Elza e Fernando Netto Boiteux ${ }^{2}$ explicam que "durante décadas a energia elétrica foi considerada uma forma de energia absolutamente 'limpa' (não poluente) e não se imaginava que ela pudesse causar nenhum dano, a não ser através do contato direto com o corpo humano, provocando os conhecidos choques elétricos". Mostram os autores que os sintomas negativos apareceram em trabalhadores expostos a maiores cargas de energia, como, por exemplo, contrações musculares involuntárias. "Os efeitos nocivos à saúde decorrentes de exposição aos campos eletromagnéticos gerados pela transmissão de energia elétrica também não se apresentam de maneira evidente, quanto os decorrentes da exposição à radiação nuclear ou aparelhos de exame por meio de raios- $\mathrm{X}^{\prime \prime}{ }^{3} \mathrm{O}$ mundo pode ficar sem energia elétrica?

Apesar da lista interminável, mencionamos, por fim, as ameaças do terrorismo internacional que não tem local e nem pátria. $O$ risco do terrorismo, que está em todas as partes sem estar em nenhuma, apavora a humanidade. Ninguém sabe se fazendo turismo, mesmo em países aparentemente pacíficos, não morrerá no próximo minuto, como, por exemplo, no maior atentado terrorista da história da Europa, no dia 11 de março de 2004, na estação de trens Atocha de Madri, que matou 200 pessoas e feriu quase 2.000, ou o ataque às Torres Gêmeas, em Nova Iorque, em 11 de setembro de 2001 , maior atentado terrorista do mundo. O terrorismo levou a um desdobramento perverso que foi o de fulminar o direito fundamental da privacidade em nome da segurança social, veja-se o sistema de revista nos aeroportos estadunidenses desnudando literalmente, seus passageiros, que, sem opção, submetem-se a essa forma de controle.

BOITEUX, Elza Antonia P. C.; BOITEUX, Fernando Netto. Poluição eletromagnética e meio ambiente. O princípio da precaução. Porto Alegre: Sergio Antonio Fabris Editora, 2008. p. 19 e 20.

3 Segundo Elza e Fernando Boiteaux, op. cit., pág. 42, nos últimos dez anos, em razão da existência de relação estatística entre a ocorrência e a radiação eletromagnética, as doenças que podem surgir são: leucemia em adultos e crianças, câncer no cérebro em adultos e crianças, câncer de mama em homens e mulheres, outros tipos de câncer, aborto espontâneo, disfunções de reprodução ou desenvolvimento, esclerose lateral amiotrófica (doença de Lou Gehrig), mal de Alzeimer, infarto agudo do miocárdio, suicídio, outras doenças como depressão. 
Contudo, por mais medidas que sejam tomadas, o risco zero não existe. Em suma, a única certeza na sociedade risco é a incerteza, pois os riscos não podem ser mensurados. A sociedade de risco, como quer Beck, é a sociedade da era industrial acrescida das inovações científicas e tecnológicas, cujos efeitos são imprevisíveis. Na verdade, os riscos sempre existiram, mas estes são os chamados novos riscos, que poderão levar a danos graves e irreversíveis às pessoas e ao meio ambiente, são os riscos do progresso. Beck mostra que a força motriz da sociedade de classes pode ser resumida em uma frase: "Tenho fome!" E, na sociedade de riscos: "Tenho medo!" Na era do risco, as ameaças com as quais nos confrontamos não podem ser atribuídas a Deus ou à natureza, mas à própria "modernização" e ao "progresso"

Por isso, Hans Jonas propôs uma nova ética, no seu prestigiado $O$ Princípio Responsabilidade, ${ }^{4}$ para salvaguardar e proteger a atual e as futuras gerações. Propõe, então, que a incerteza que domina a sociedade contemporânea e que ameaça tornar inoperante uma responsabilidade em relação ao futuro seja incluída na teoria ética, daí surgindo um novo princípio como prescrição prática: "é necessário dar mais ouvidos à profecia da desgraça do que à profecia da salvação" (grifo do autor). ${ }^{5}$ Há, dentro do Princípio Responsabilidade, um dever para com o futuro, com a humanidade, para que esta humanidade continue a existir.

2. Os princípios da prevenção e da precaução

O Direito, a mais importante ciência social, vem tentando acompanhar essas transformações, sempre alguns passos atrás, para continuar sua missão, ou seja, organizar a sociedade de forma segura e justa. Cria, então, instrumentos que venham evitar ou amenizar a possibilidade desses novos riscos, que poderão levar a danos graves e irreversíveis. Aparecem, dessa forma, os princípios jurídicos da prevenção e da precaução.

O princípio da prevenção vai ser aplicado quando o risco de dano é concreto e real. Na verdade estamos diante do perigo, que é o risco conhecido, como, por exemplo, o limite de velocidade nas estradas ou os exames médicos necessários que antecedem uma intervenção cirúrgica. Podemos lembrar, a propósito, que o princípio da prevenção perpassa todo Direito do Consumidor, pois o Código de Defesa do Consumidor consagra a obrigação de segurança quando determina, em seu artigo $6^{\circ}$, I, que é direito básico do consumidor a "proteção da vida, saúde e segurança contra os riscos provocados por práticas no fornecimento de produtos e serviços considerados perigosos ou nocivos"

4 Hans Jonas, O Principio Responsabilidade. Tradução Marijane Lisboa e Luiz Barros Nuntez, Rio de Janeiro: Ed. Contraponto, PUC, 2006.

5 Op. cit., p. 77. 
Sem dúvida, o código consumerista tem como "regras de fundo" os princípios da prevenção e da precaução.

Já o princípio da precaução deve ser aplicado no caso de riscos potenciais ou hipotéticos, abstratos, e que possam levar aos chamados danos graves e irreversíveis. É o "risco do risco" "Neste caso, não há dúvida que os atores desse momento devem identificar e construir esse risco (os atores são o poder público, as empresas, a mídia, a sociedade civil, os profissionais liberais e o próprio indivíduo) com base nas estatísticas, perícias, probabilidades, pesquisas de opinião e auxílio da mídia.

O grande dilema nessa questão é verificar se as medidas antecipatórias do risco devem ser tomadas. Exemplo: Nos anos 80 na França, desconfiava-se, apenas dúvida havia, frise-se, que certo grupo de pessoas poderiam estar contaminadas com o vírus $\mathrm{HIV}$, que ainda não se encontrava isolado. Contudo, nenhuma medida foi tomada diante da continuidade dos procedimentos de doação de sangue. Assim, muitas pessoas foram contaminadas, principalmente os hemofílicos. Faltou a aplicação do princípio da precaução; por outro lado, se aplicado incondicionalmente, pode causar danos econômicos e sociais irreversíveis. Tome-se como paradigma o caso dos alimentos transgênicos sobre os quais pairam dúvidas em ambos sentidos: seriam bons ou maléficos à saúde humana? Não se sabe ao certo, mas pode-se dizer que, se o seu cultivo fosse barrado em nome da precaução, as exportações brasileiras sofreriam um estrondoso golpe e, por conseqüência, os trabalhadores diretamente e a população pelo empobrecimento.

A precaução e a prevenção sempre existiram como manifestação da prudência, mas eram aplicadas de forma intuitiva. Hoje, na sociedade contemporânea, como medida preventiva, é de aplicação técnica para os novos riscos.

A noção de precaução foi introduzida pelo Direito Ambiental e sua consagração se deu em 1992 na Declaração do Rio, a ECO 92, que determina, em seu princípio 15: “Com o fim de proteger o meio ambiente, o princípio da precaução deverá ser amplamente observado pelos Estados, de acordo com suas capacidades. Quando houver ameaça de danos graves ou irreversíveis, a ausência de certeza científica absoluta não será utilizada como razão para o adiamento de medidas economicamente viáveis para prevenir a degradação ambiental." Do Direito Ambiental passou para o Direito Sanitário, vide de casos de HIV e doença da "vaca louca" assim como para o âmbito médico-hospitalar, vindo desembocar na Teoria Geral da Responsabilidade Civil.

A Responsabilidade Civil assume cada vez mais sua autonomia científica e jurídica, mesmo fazendo parte do Direito das Obrigações. Nela, os princípios da prevenção e precaução se manifestam na atitude ou na conduta de antecipação de riscos graves e

6 KOURILSKY, Philippe; VINEY, Geneviéve. Le principe de précaution. Paris: Editions Odile Jacob, 2000, p. 16. 
irreversíveis. Exemplos: Na área da saúde, o gerenciamento de vacinas, de tratamentos e de infecção hospitalar. Nos transportes, a exigência de cada vez mais de máxima segurança. Nos alimentos o monitoramento dos agrotóxicos, alimentos contaminados e regras para obtenção de organismos geneticamente modificados - OGMs. Em todos os tipos de produtos, principalmente no rastreamento dos remédios, que podem ter efeitos tardios perniciosos (riscos de desenvolvimento), bem como o recall de automóveis, brinquedos e outros bens de consumo.

Porém, como já falamos anteriormente, o risco zero não existe. Sempre teremos o chamado risco residual, que tem sido absorvido pelas vítimas.

Em suma, os princípios da precaução e da prevenção já estão fazendo parte da Responsabilidade Civil do século XXI e devem ser aplicados de forma equilibrada dentro dos princípios da razoabilidade e da proporcionalidade. O princípio da precaução é uma arma perigosa nas mãos dos demagogos e dos políticos populistas. Assim, empresas que estão colaborando com o progresso e crescimento do país, e que ajudam socialmente com o fornecimento de empregos diretos e indiretos e com a distribuição de certos benefícios sociais, podem ser obrigadas a fechar suas portas, acusadas de omissões no gerenciamento dos riscos que vêm de seus produtos e serviços por não terem adotado medidas de prevenção no caso de risco conhecido ou de precaução no caso de riscos possíveis, o que pode não ser verdadeiro. Podem travar o progresso econômico, científico e social.

3. Fundamentos ético e jurídico do princípio da precaução e as funções da responsabilidade civil no século XXI

O fundamento ético do princípio da precaução está na virtude da prudência, como a definiu Aristóteles: o comportamento diante do incerto. Já vimos, anteriormente, que Hans Jonas tem outro fundamento para esse princípio, qual seja, a ética do medo.

Os fundamentos jurídicos, por sua vez, são vários. O primeiro é, sem dúvida, a obrigação geral de segurança positivada na Constituição federal e no Código de Defesa do Consumidor.

François Ewald, ${ }^{7}$ um dos principais autores na matéria, acha que a sociedade está mudando de paradigma no que diz respeito à filosofia política da segurança e das obrigações sociais. Esclarece que o século XIX teve como paradigma a "responsabilidade" (compensação das perdas). Na passagem para o século XX, esse paradigma da responsabilidade foi substituído pelo da solidariedade (Estado-Providência

EWALD, François; GOLLIER. Christian; SADELEER, Nicolas de. Le principe de précaution. In: COLEÇÃO Que sais-je? Paris: PUF, 2001. 
e garantia de indenização pela segurança, o que veio a desembocar na "socialização do risco" como vimos). Supõe que agora pode ser que estejamos no momento de assistir ao nascimento de um novo paradigma, ou seja, da segurança que faz aparecer uma nova economia de direitos e deveres. Antes a noção de risco satisfazia; agora, há uma noção a ser reconhecida, a de incerteza. As obrigações morais tomam a forma da ética e a responsabilidade aparece como reflexo da noção de precaução. Assim, é o paradigma da segurança que transforma os princípios da responsabilidade e da solidariedade em princípio da precaução. Esse paradigma tem, no princípio da precaução, sua melhor aposta.

A obrigação geral de segurança veio se acrescentar à reparação integral e à solidariedade, ou seja, a responsabilidade civil foi enriquecida, evoluiu. Não há exclusão de nenhum dos paradigmas anteriores.

No direito brasileiro, podemos fundamentar juridicamente o princípio da precaução:

$\left.1^{\circ}\right)$ No artigo $3^{\circ}$ da Constituição Federal de 1988, que determina que constitui objetivo fundamental da República Federativa do Brasil "I - construir uma sociedade livre, justa, solidária" Portanto, a solidariedade é objetivo fundamental da República. Esse princípio tem que ser usado sempre, pois vai iluminar a interpretação das normas, porquanto é ele um dos pilares que ajudam a construir o sistema jurídico pátrio. Não poderia deixar de aplicar-se à responsabilidade civil, que é o ramo do direito que vela para que os danos não fiquem impunes (alterum non laedere) e agora também para que os riscos e danos sejam evitados.

$\left.2^{\circ}\right)$ Cite-se também o artigo $5^{\circ}$ : XXXV, onde se lê: "a lei não excluirá da apreciação do Poder Judiciário lesão ou ameaça a direito"

$\left.3^{\circ}\right)$ Também são fundamentados os princípios da precaução e da prevenção no caput do artigo $5^{\circ}$, do título II da Constituição Federal de 1988, que trata dos "Direitos e Garantias Fundamentais" O artigo $5^{\circ}$ dispõe que "Todos são iguais perante a lei, sem distinção de qualquer natureza, garantindo-se aos brasileiros e aos estrangeiros o direito à vida, à liberdade, à igualdade, à segurança e à propriedade, (...)" Completa essa proteção constitucional a norma do artigo $6^{\circ}$ insculpida no Capítulo II dos "direitos sociais" que determina que "São direitos sociais a educação, a saúde, o trabalho, o lazer, a segurança, a previdência social, a proteção à maternidade e à infância (...)" Portanto, a segurança aparece como um direito e garantia individual e coletiva e também como direito social. A precaução tem como objetivo direto a segurança individual e social, ou melhor, é um dos modos pelos quais se faz a gestão de riscos, riscos esses graves, irreparáveis e incertos. $\mathrm{O}$ princípio da precaução vai desenvolver o princípio da segurança.

$\left.4^{\circ}\right)$ Sem dúvida, também há os fundamentos estatutários, isto é, do direito infraconstitucional, como o Código de Defesa do Consumidor, que prevê expressamente a obrigação geral de segurança afeta ao fornecedor de produtos e serviços que ameacem a 
saúde, a vida e a segurança dos consumidores. É direito básico do consumidor "a proteção à vida, à saúde e à segurança contra riscos provocados por práticas no fornecimento de produtos e serviços considerados perigosos ou nocivos" (artigo $6^{\circ}, \mathrm{I}, \mathrm{CDC}$ ). Além disso, o consumidor tem expectativa de segurança nos produtos e serviços postos no mercado. O Código de Defesa do Consumidor, visando proteger a parte mais fraca e vulnerável, tem como "regras de fundo" os princípios da prevenção e da precaução, obrigatórios para os fornecedores de produtos e serviços. O mesmo acontece com as leis ambientais, que exigem essa precaução para que o meio ambiente e, por conseqüência, as pessoas não fiquem prejudicados com seu mau uso ou uso abusivo.

$5^{\circ}$ ) Podemos lembrar a Declaração do Rio de Janeiro, de 1992, que, em seu princípio 15 , prevê expressamente o princípio da precaução ("De modo a proteger o meio ambiente, o princípio da precaução deve ser amplamente observado pelos Estados, de acordo com suas capacidades. Quando houver ameaça de danos sérios e irreversíveis, a ausência de absoluta certeza científica não deve ser utilizada como razão para postergar medidas eficazes e economicamente viáveis para prevenir a degradação ambiental"), que exprime de modo claro quando o princípio da precaução deve ser aplicado. A lei da responsabilidade em atividades nucleares (lei $n^{\circ} 6.453$ de 1977) consagra a responsabilidade irrestrita por danos nucleares e, em matéria de precaução, prevê a responsabilização penal daquele que, ao explorar atividade nuclear, não observar as normas de segurança relativas à instalação nuclear e ao manuseio do material nuclear (artigo 26).

$6^{\circ}$ ) Todos os ordenamentos nacionais e supranacionais que tratam do princípio da precaução.

$7^{\circ}$ ) Porém, de outro lado, temos, para fundamentar juridicamente o princípio da precaução, em sua aplicação na prática jurisdicional, a analogia legis, ou seja, podemos aplicar para casos semelhantes e com a mesma razão de direito o princípio 15 da Carta do Rio de 1992, que exprime de maneira clara quando o princípio da precaução deve ser aplicado. Assim, diante da lacuna sobre a precaução, o intérprete usará a norma prevista para hipótese semelhante.

$8^{\circ}$ ) Finalmente, o fundamento da precaução e também da prevenção como princípios jurídicos pode vir dos princípios inspiradores do sistema (analogia juris), como o princípio da segurança, o princípio da ética social, o princípio da função social da propriedade e dos contratos, o princípio da dignidade humana, o princípio da solidariedade, o princípio do respeito à vida, à saúde, à propriedade, o princípio da igualdade substancial no plano individual e global, o princípio da reparação integral dos danos. Assim como dos princípios gerais de direito, de conhecimento universal. Lembraríamos principalmente o alterum non laedere, "deve-se fazer o bem e evitar o mal" "deve-se respeitar o próximo" "deve-se manter a vida em sociedade" "deve-se pensar nas gerações futuras" 
Em resumo, a partir da admissão dos princípios dả precaução e da prevenção, podemos dizer que a Responsabilidade Civil do século XXI tem três funções principais:

1. Função compensatória: sua função principal, fundamentada no princípio da reparação integral de todos os danos sofridos;

2. Função dissuasória: aparece através de pesadas indenizações contra o autor do dano, classicamente chamada de função preventiva, dentro da qual temos que lembrar a teoria dos punitive damages, com caráter de pena privada, e da deterrence com fundamento econômico.

3. Função preventiva em sentido lato: engloba os princípios da precaução e da prevenção, pelos quais haverá a antecipação de riscos e danos.

Com isso nasce a responsabilidade preventiva, que funcionará ao lado da responsabilidade reparadora ou clássica. Uma não exclui a outra. Ambas são necessárias, pois, caso o dano não consiga ser evitado, deverá ser reparado integralmente por seu autor ou pelo seguro. Portanto, diante da sociedade de risco, teve a responsabilidade civil que evoluir acrescentando os princípios da precaução e da prevenção ao seu rol já tradicional de princípios. Houve apenas acréscimo sem recuo ou perda de importância, seja da culpa, seja do risco. Essa transformação que vivemos na sociedade atual é semelhante àquela que levou à introdução da responsabilidade objetiva e coletiva em um sistema todo fundamentado na responsabilidade individual e na culpa.

4. A aplicação e execução do princípio da precaução. Responsabilidade sem dano

A Responsabilidade Civil por ameaças ou riscos de danos graves e irreversíveis pode ser executada por meio de medidas preventivas e acautelatórias no âmbito privado. Um bom exemplo é o da aplicação dessas medidas juntamente com os dispositivos legais dos direitos de vizinhança, que, sem dúvida, podem ser utilizados com base na analogia juris, lembre-se o citado caso do Tribunal de Grasse, França. No âmbito público, órgãos administrativos como a ANVISA, o CADE, o PROCON, o IBAMA, a ANAC etc. aplicam de forma expressa norma e sanções com caráter indubitavelmente precaucional.

O problema da prevenção e precaução se coloca principalmente nos casos de responsabilidade sem dano. Mas como é isso possível se a Responsabilidade Civil trata da reparação de danos e, em consequência, sem dano provado não há lugar para a reparação? Para equacionar esse problema é preciso separar os conceitos de responsabilidade e indenização, porquanto são noções distintas. A noção de responsabilidade viu seu campo expandido com o aparecimento da "sociedade de risco" e, neste momento, é somente a teoria da responsabilidade civil que poderá definir e tutelar os "novos riscos" causadores do também novo tipo de dano, aquele muito grave e irreversível. 
Será possível caracterizar como dano (prejuízo) a ameaça ou risco de "danos graves e irreversíveis"? Existiria o "dano de risco"? Pensamos que é possivel na teoria e na prática. Ainda nos socorrendo do direito à saúde, podemos lembrar de situações em que pessoas tiveram contato com algum vírus, mas não desenvolveram a doença ou porque ainda não passou o período da chamada "janela imunológica", como no caso da AIDS, e não é possível averiguar se o exame vai dar positivo ou negativo; ou, então, porque há um lapso de tempo muito grande entre o contato e o desenvolvimento da doença, como no caso da temida "hepatite C" Poderá pedir indenização pela ameaça ou risco de desenvolver a doença? O medo constante de ser portador de vírus de doença incurável é, com certeza, dano indenizável. Também poderíamos colocar a hipótese de uma ação civil pública contra o Município do Rio de Janeiro, em nome de toda a população carioca (não somente dos já contaminados), pelo risco de adquirir dengue por falta de precaução da Prefeitura do Rio de Janeiro. $\mathbf{O}$ dano aqui é o risco.

Todavia, Mathilde Boutonnet faz diferença entre risco e perturbação por uma ameaça de dano. Cita um julgado no qual fotografias tiradas de determinada pessoa sem sua autorização expressa podem configurar um dano resultante "do risco que uma tal publicação pode mexer com a segurança sobre seus bens" Foi essa perturbação que foi reparada, e não o risco, segundo autora ${ }^{8}$

Enfim, ressaltamos que a solução é sempre a aplicação do princípio da precaução, tendo em vista que os riscos são hipotéticos. A precaução consistirá no gerenciamento desses riscos por meio da informação (como no caso dos telefones celulares), porém somente quando a ciência tiver alguma base para diminuir esses possíveis riscos é que deverá ser adotada alguma atitude efetiva de prevenção e precaução.

5. Conclusões: A solidariedade e o dilema entre a socialização dos riscos e a prevenção de danos

A responsabilidade fundada no risco tem não só fundamento econômico (ubi emolumentum ibi onus), mas também ético, de uma ética social (ethos), que se resume na solidariedade.

O princípio solidarista aparece nas Constituições européias do último pósguerra e também integra a Constituição Federal brasileira de 1988. Constitui um dos objetivos fundamentais da República do Brasil construir uma sociedade livre, justa e solidária (art. $3^{\circ}$, I). Alcança seu pleno desenvolvimento com a instituição dos Welfare States.

BOUTONNET, Mathilde. op. cit., p. 527-529. 
Dessa forma, a doutrina da "socialização dos riscos" tem fundamento ético na solidariedade social como necessidade de reparação integral de todos os danos. Há de se proteger as vítimas. Os riscos criados não se consideram mais simples riscos individuais. São riscos sociais e não é justo que os homens respondam por eles individualmente. A regra do neminem laedere tem muito mais um caráter social que individualista. O que importa é que se repartam as conseqüências danosas entre todos os membros da sociedade. O risco se coletiviza. Socializa-se a responsabilidade, no dizer de Savatier. ${ }^{9}$

A socialização dos riscos tem como pilares o seguro social e o seguro privado de responsabilidade civil. No dizer de J. J. Calmon de Passos, "para se tornar operacional a teoria do risco, sem disfuncionalidade, impôs-se a solução pelo seguro, que institucionaliza, em termos técnicos, o imperativo de solidariedade" ${ }^{10}$ Mas, a verdadeira "socialização dos riscos" é aquela na qual há a difusão do seguro obrigatório e a criação dos Fundos estatais ou também de fundos que, além das reservas provindas do Poder Público, se mantêm com a contribuição financeira das empresas que mais expõem a riscos a sociedade. Sem a adoção geral do seguro obrigatório é impossível falar-se em "socialização dos riscos"

Alpa e Bessone mostram que a tendência da socialização dos riscos e dos custos nas atividades empresariais causadoras de danos não tem fundamento na revisão das regras de responsabilidade, mas na substituição dos instrumentos de direito privado pelos publicísticos. ${ }^{11}$

Em outras palavras, a socialização dos riscos depende do Seguro Social e do seguro privado obrigatório (com ação direta da vítima), pois, se for facultativo, não haverá solução do problema das indenizações. O seguro obrigatório torna, definitivamente, a responsabilidade civil objetiva e o ressarcimento certo para todas as vítimas. Não importa o autor do dano; é a vítima que importa. Mister, em outros dizeres, a prevenção e a precaução dos perigos e desastres, pois, mesmo que as indenizações sejam vultosas, o mais importante é o respeito à integridade física e psíquica da pessoa humana.

Da mesma forma, na socialização dos riscos, perde importância a fundamentação da responsabilidade na teoria da culpa ou do risco. Na verdade, estamos diante do "direito de danos" e não da responsabilidade em sentido estrito.

Finalmente, a ampla "socialização dos riscos" pode tirar o incentivo da tomada de precaução diante dos riscos e da prevenção de perigos, pois o seguro é o oposto da conduta preventiva. Deveríamos ter um sistema que privilegiasse os princípios da

SILVA, Wilson Melo da. Responsabilidade sem culpa e socialização do risco. Belo Horizonte: Ed. Bernardo Alvares S.A., 1962.

10 "O Risco na Sociedade Moderna e seus Reflexos na Teoria da Responsabilidade Civil e na Natureza Jurídica no Contrato de Consumo", in Revista Diálogo Jurídico, ano I, vol. I, n 5, agosto de 2001, Salvador, Bahia.

" ALPA, Guido; BESSONE, Mario. Tratatto di diritto privato. Torino: UTET, 1986. t. 6, v. 14, p. 320. 
precaução e da prevenção e, no caso de essas medidas falharem vindo a causar danos, aí sim o seguro iria socorrer as vítimas. É preciso ressaltar que a socialização dos riscos não acaba com os riscos, ao contrário, pode tornar os responsáveis por eles menos cuidadosos.

São Paulo, dezembro de 2010.

\section{Referências}

ALPA, Guido; BESSONE, Mario. Tratatto di Diritto Privato. Torino: UTET, 1986. t. 6, v. 14.

BAUMAN, Zygmunt. Medo Líquido. Tradução de Carlos Alberto Medeiros. Rio de Janeiro: Ed. Zahar, 2008.

BOITEAUX, Elza Antonia P. C.; BOITEAUX, Fernando Netto. Poluição eletromagnética e meio ambiente. O princípio da precaução. Porto Alegre: Sergio Antonio Fabris Editora, 2008.

BOUTONNET, Mathilde. Le principe de précaution en droit de la responsabilité civile. Paris: L.G.D.J, 2005.

PASSOS, J. J. Calmon de. O risco na sociedade moderna e seus reflexos na teoria da responsabilidade civil e na natureza jurídica no contrato de consumo. Revista Diálogo Jurídico, Salvador, a. 1, v. 1, n. 5 , agosto 2001 .

EWALD, François; GOLLIER, Christian; SADELEER, Nicolas de. Le principe de précaution. In: COLEÇÃO Que sais-je? Paris: PUF, 2001.

GIDDENS, Anthony. Runaway world, how globalization is reshaping our lives. New York: Ed. Routledge, 2000.

GODARD, Olivier. Le principe de précaution: dans la conduite des affaires humaines. Paris: Editions de la Maison des sciences de l'homme, 1997.

JONAS, Hans. O principio responsabilidade. Tradução Marijane Lisboa e Luiz Barros Nuntez. Rio de Janeiro: Ed. Contraponto, PUC, 2006.

KOURILSKY, Philippe Kourilsky; VINEY, Geneviéve. Le principe de précaution. Paris: Editions Odile Jacob, 2000.

LOPEZ, Teresa Ancona. Principio da precaução e evolução da responsabilidade civil. São Paulo: Quartier Latin, 2010.

MORSELLO, Marco Fabio. A responsabilidade civil e a socialização dos riscos: o sistema neozelandês e a experiência escandinava. Revista da Escola de Magistratura, a. 7, n. 2, jul./dez. 2006 .

SILVA, Wilson Melo da. Responsabilidade sem culpa e socialização do risco. Belo Horizonte: Ed. Bernardo Alvares S.A., 1962. 
THIBIERGE, Catherine. Libres propos sur l'évolution du droit de la responsabilité. Revue Trimestrielle de Droit Civil, Paris, n. 3, jul./set. 1999.

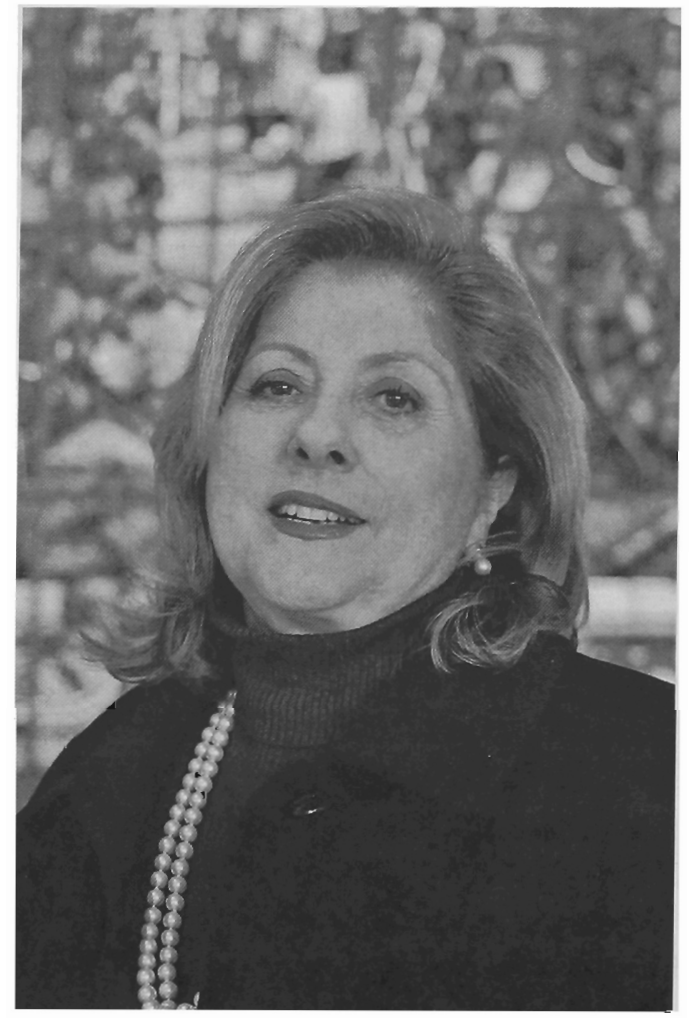

Professora Teresa Ancona Lopez 